\title{
Pemanfaatan Smartphone Berbasis Android Sebagai Alat Pengontrol Pembersih Lantai
}

\author{
Ratnasari Nur Rohmah, Nindya Kaloka \\ Teknik Elektro \\ UMS \\ Surakarta, Indonesia \\ nindyakaloka77@gmail.com
}

\begin{abstract}
Abstraksi-Di era kemajuan teknologi saat ini kemudahan dan kepraktisan dalam melakukan sesuatu banyak dibutuhkan untuk membantu kegiatan manusia dalam keseharian. Penggunaan smartphone berbasis android sebagai alat komunikasi yang cangih dapat memberikan solusi untuk mengembangkan suatu alat konvensional menjadi alat yang modern. Berdasarkan permasalahan yang dijabarkan, maka tujuan penelitian ini yaitu merancang alat pembersih lantai yang praktis dan mudah dioperasikan menggunakan smartphone berbasis android. Alat pembersih lantai ini dibuat dengan desain robot penyedot kotoran sederhana yang memiliki empat roda dimana dua roda sebagai penggerak dan dua lainnya sebagai follower. Penggerak roda menggunakan motor DC yang dikendalikan oleh motor L289N. Pada aplikasi android yang ada di smartphone digunakan sebagai pengendali jarak jauh pergerakan pembersih lantai. Pengendalian dilakukan dengan pemilihan tombol gerakan maju, mundur, belok kanan, belok kiri, dan stop. Rangkaian kontrol menggunakan bluetooth HC-05 sebagai penerima data dan mikrokontroler arduino sebagai pengolah data. Data yang diterima dari smartphone diolah untuk menggerakkan rangkaian motor DC. Alat ini dilengkapi sensor ultrasonik HC-SR04 sebagai pengontrol jarak antara alat pembersih lantai dengan dinding atau benda lainnya.
\end{abstract}

Katakunci-Android, Arduino, Bluetooth, Motor DC

\section{PENDAHULUAN}

Pesatnya perkembangan teknologi saat ini menjadikan kecenderungan pemanfaatan teknologi menjadi semakin luas.Peralatan berbasis robot merupakan salah satu aplikasi teknologi yang banyak dikembangkan untuk membantu pekerjaan manusia. Peralatan ini menggabungkan teknologi mekanik dan elektronik yang dirancang untuk membantu bahkan menggantikan pekerjaan manusia.[6].

Aktivitas kerja yang dilakukan manusia dalam kehidupan sehari-hari sangatlah beragam, baik aktivitas dalam ruangan maupun diluar ruangan. Ruangan merupakan suatu tempat dimana hampir $90 \%$ manusia lebih banyak beraktivitas di dalam ruangan daripada di luar ruangan[3]. Sebagai sarana beraktivitas, tentunya perawatan ruangan merupakan hal yang harus diperhatikan, salah satunya adalah dalam hal kebersihan lantai ruangan.Membersihkan lantai merupakan kegiatan yang sering dikerjakan dan pekerjaan ini tidak hanya dikerjakan sekali saja, namun dikerjakan secara rutin setiap harinya.

Pada umumnya pembersih lantai khususnya pembersih debu menggunakan material kain atau nylon untuk membersihkan debu tersebut. Seiring berkembangnya teknologi, kini alat pembersih lantai menggunakan teknologi penyedot debu atau yang sering disebut vacuum cleaner. Peralatan ini menggunakan manusia sebagai pengendalinya untuk mengarahkan peralatan tersebut dan juga menggunakan kabel yang cukup panjang untuk membersihkan beberapa bagian lantai yang jaraknya cukup jauh[1].

Bluetoothmerupakan salah satu alternatif teknologi wireless yang dibuat untuk peralatan mobile (mobile device).Bluetooth menggunakan frekuensi $2,4 \mathrm{GHz}$ dengan kecepatan transfer data kurang dari 1 Mbps atau sekitar 800 Kbps. Oleh karena itu, perangkat ini dapat diaplikasikan dalam alat pembersih lantai[5].Bantuan wireless berupa teknologi bluetooth akan sangat memudahkan dalam proses mengirim perintah dari aplikasi android dan diteruskan ke mikrokontroler yaitu arduino yang akan melakukan gerakan maju, mundur, belok kanan, belok kiri maupun stop dan juga menjalankan fungsi utama dalam menyedot debu atau kotoran.yang dilewati dengan bantuan sensor ultrasonik untuk mengetahui jarak alat dengan benda yang ada disekitarnya.

Adanya kelemahan peralatan vacuum cleaner konvensional memberikan tantangan bagi para inovator untuk mengembangkan peralatan berbasis tekonologi yang dapat mengatasi kelemahan tersebut.Menggunakan teknologi android merupakan cara yang sangat efektif untuk megendalikan suatu perangkat dari jarak jauh. Selain itu aplikasi yang dirancang dapat memberikan kemudahan dan menghemat waktu pada manusia dalam melaksanakan aktivitasnya sehari - hari[7].

\section{METODE}

Perancangan alat pembersih lantai yang ditunjukkan menggunakan arduino uno, sensor ultrasonik HC-SR04, rangkaian motor DC, driver L298N, smartphone android, 
bluetooth HC - 05, LED, buzzer, rangkaiam vacuum dan power supply. Arduino Uno pada perancangan ini digunakan sebagai akuisisi data yang menghubungkan perangkat keras dengan perangkat lunak sebagai kontrol dan penyimpanan data[2]. Android akan mengirimkan data ke arduino melalui jaringan bluetooth kemudian mengintruksikan motor driver L298N untuk menggerakkan roda motor DC maju, mumdur maupun belok sesuai pilihan tombol yang ditekan pada layar smartphone dan juga menjalankan fungsi utama dalam menyedot debu atau kotoran yang dilewati dengan bantuan sensor ultrasonik untuk mengetahui jarak alat dengan benda yang ada disekitarnya. LED dan buzzer sebagai indikator peringatan baterai dan jarak.

\section{A. Perancangan Sistem}

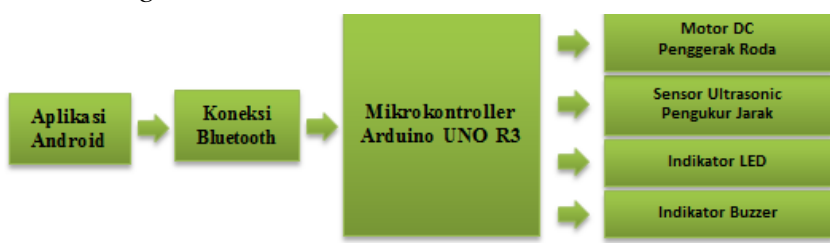

.Gambar 1. Diagram Blok Perancangan Sistem

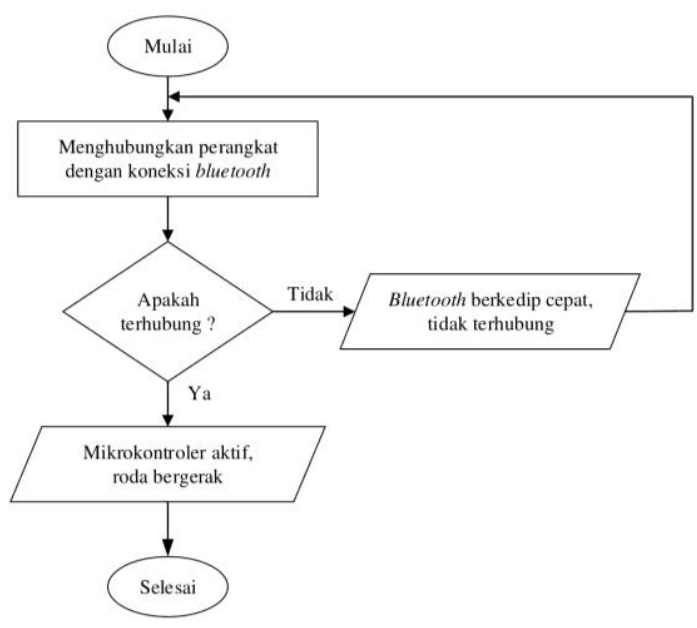

Gambar 2. Flowchart Alat Pembersih Lantai

Flowchart alat pembersih lantai pada Gambar 2 dimulai dari proses menghubungkan perangkat android dengan perangkat mikrokontroler menggunakan koneksi bluetooth. Jika sudah terhubung, kemudian perangkat akan membaca data yang masuk. Data pada perangkat hardware masuk dari deteksi yang dilakukan oleh sensor ultrasonik dengan menampilkan jarak pada layar aplikasi dan juga mengaktifkan rangkaian mikrokontroler sehingga roda dapat bergerak sesuai dengan data yang diterima dari aplikasi android.

\section{B. Desain Hardware}

Pembuatan desain alat pembersih lantai menyesuaikan semua komponen elektronika agar pergerakan roda yang dihubungkan dengan motor DC dan dikendalikan melalui aplikasi android dapat bekerja dengan baik dan benar. Desain ini dibuat dengan menggunakan komponen seperti motor DC, driver motor L298N, bluetooth HC-05, Sensor ultrasonik HCSR04 dan power supply. Desain secara keseluruhan dalam perancangan ini dibuat dengan softwarecoreldraw seperti Gambar 3.
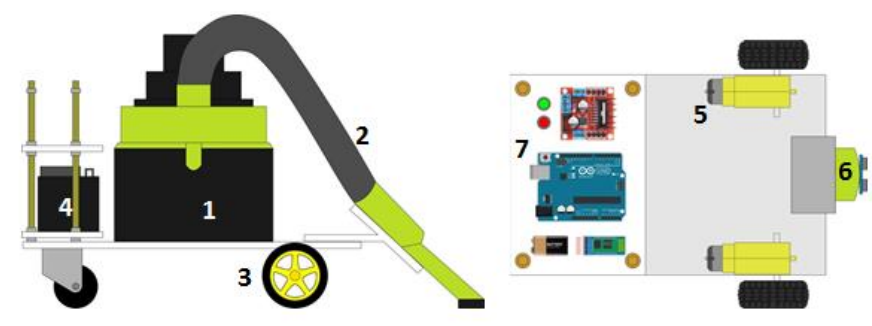

Gambar 3. Desain Keseluruhan dengan Corldraw

\section{Rangkaian Elektronika Alat}

Rangkaian skematik alat menggunakan software eagle yang ditunjukkan pada Gambar 4. Skematik ini digunakan untuk menentukan letak komponen yang terpasang yaitu motor driver L298N, bluetooth HC-05, sensor ultrasonik HCSR04 dan power suplay pada pin - pin arduino. Penggunaan power supply 12 volt untuk memberikan catu daya pada motor driver L298N dan kipas vacum agar dapat berfungsi optimal. Sedangkan tegangan yang masuk ke arduino juga menggunakan catu daya yang berkapasitas 12 volt karena arduino hanya membutuhkan kapasistas tegangan 5 volt karena sudah terdapat regulator yang berfungsi sebagai penurun tegangan sehinga pin pada arduino dapat digunakan komponen lainnya [4].

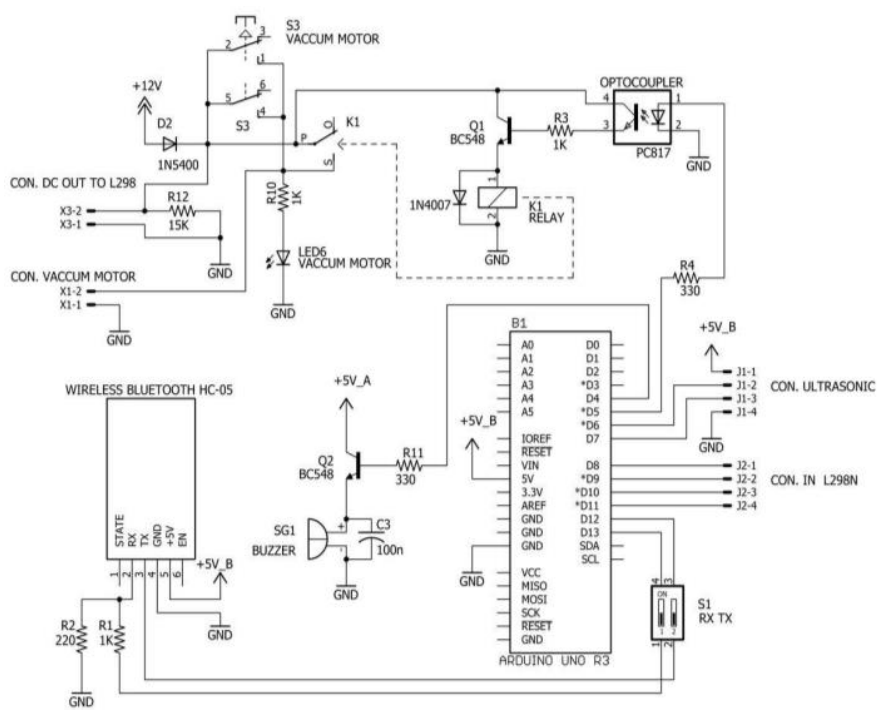

Gambar 4. Skema Rangkaian Alat Pembersih Lantai 


\section{Desain Software Aplikasi}

Pembuatan software aplikasi dalam alat pembersih lantai ini menggunakan app invertor. Desain yang dibuat menggunakan desain sederhana terdiri pemilihan empat tombol yaitu maju, mundur, kanan, dan kiri. Aplikasi ini memanfaatkan jaringan bluetooth yang ada pada smartphone sebagai sarana pengiriman data ke perangkat mikrokontroler.

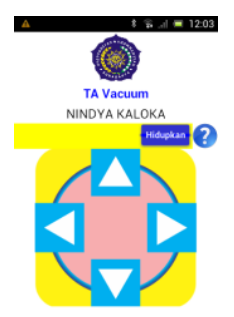

Gambar 5. Tampilan Aplikasi Android

\section{HASIL DAN PEMBAHASAN}

\section{A. Hasil Hardware Alat Pembersih Lantai}

Alat pembersih lantai ditunjukkan pada Gambar 6, sensorultrasonik HC-SR04 ditunjukkan pada nomer 1 sebagai pendeteksi beda yang ada disekitar. Buzzer sebagai alarm pengingat suara jika ada benda yang terdeteksi pada sensor ultrasonik ditunjukkan pada nomer 2 sebagai indikator keadaan kondisi baterai. LED yang ditunukkan nomor 3 . Saklar ON / OFF terdapat pada nomor 4.
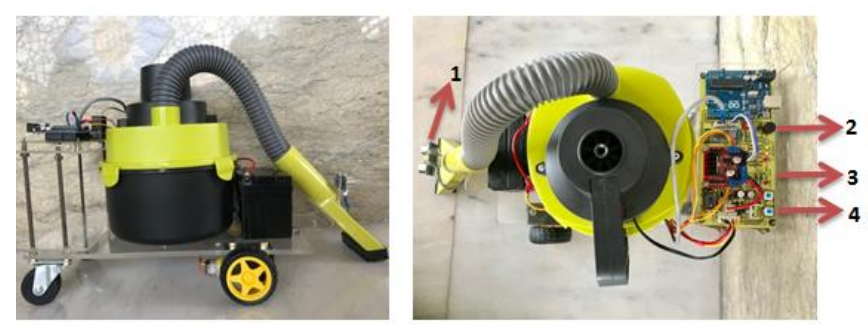

Gambar 6. Alat Pembersih Lantai

B. Hasil Pengujian Pengukuran Tegangan, Arus, dan Daya

TABEL 1. PENGUKURAN TEGANGAN, ARUS, DAN DAYA

\begin{tabular}{|c|l|c|c|c|}
\hline No. & Pengukuran & $\begin{array}{l}\text { Tegangan } \\
\text { (Volt) }\end{array}$ & Arus (Ampere) & Daya (watt) \\
\hline 1 & Vacuum ON & $11,9 \mathrm{~V}$ & \multicolumn{1}{|c|}{$4,22 \mathrm{~A}$} & \multicolumn{1}{|c|}{50 watt } \\
\hline 2 & $\begin{array}{l}\text { Vacum + } \\
\text { motor ON }\end{array}$ & $11,8 \mathrm{~V}$ & $\begin{array}{l}\text { Maju :4,9 A } \\
\text { Mundur : 5 A }\end{array}$ & $\begin{array}{l}\text { Maju }: 89 \text { watt } \\
\text { Mundur : 60 } \\
\text { watt }\end{array}$ \\
\hline 3 & Motor ON & $11,6 \mathrm{~V}$ & $\begin{array}{l}\text { Maju : 1,62A } \\
\text { Mundur : 1,84 A }\end{array}$ & $\begin{array}{l}\text { Maju : 27 watt } \\
\text { Mundur : } \\
\text { watt }\end{array}$ \\
\hline
\end{tabular}

Pengujian pengukuran tegangan, arus dan daya pada alat pembersih lantai pada tabel 1 menggunakan tacho meter sebagai alat pengukuran. Pengukuran dilakukan sebanyak 5 kali yaitu pada saat vacuum $\mathrm{ON}$, vacuum dan motor ON pada posisi maju maupun mundur, serta motor ON pada posisi maju dan mundur. Hasil yang di dapat pada pengukuran tegangan, nilai yang terbesar didapat pada kondisi hanya vacuum ON yaitu 11,9 volt dan hasil paling kecil pada saat kondisi motor ON yaitu 11,6 volt. Pada pengukuran arus, pengukuran terbesar di dapat pada saat kondisi vacuum dan motor nyala bersama yaitu 5 ampere pada posisi mundur dan pengukuran terkecil didapat pada kondisi motor ON yaitu 1,62 ampere dapa posisi motor mundur. Sedangkan untuk daya yang terpakai nilai terbesarnya yaitu 89 watt dan daya paling kecil 19 watt.

\section{Hasil Pengujian Bluetooth}

TABEL 2. PENGUJIAN BLUETOOTH

\begin{tabular}{|c|c|c|}
\hline No. & Jarak & Transfer Data \\
\hline 1 & 1 Meter & 0,15 detik \\
\hline 2 & 3 Meter & 0,15 detik \\
\hline 3 & 5 Meter & 0,23 detik \\
\hline 4 & 7 Meter & 0,28 detik \\
\hline 5 & 10 Meter & 0,39 detik \\
\hline 6 & 12 Meter & 1,19 detik \\
\hline 7 & 15 Meter & 1,27 detik \\
\hline 8 & 17 Meter & Tidak Terkirim \\
\hline 9 & 20 Meter \\
\hline
\end{tabular}

Hasil dari pengujian transmisi bluetooth menunjukkan hasil sesuai dengan yang diinginkan pada Tabel 2 didapat hasil untuk pengujian di atas jarak 15 meter pengiriman data terhambat (delay). Sedangkan jarak di atas 20 meter tidak terhubung dan transfer data tidak terkirim karena jangkauan jarak efektif modul bluetooth $\mathrm{HC}-05$ terkoneksi dalam range 10 meter.

\section{Hasil Pengukuran Hardware Alat Pembersih Lantai}

TABEL 3.SPESIFIKASI ALAT PEMBERSIH LANTAI

\begin{tabular}{|c|l|c|}
\hline No. & \multicolumn{1}{|c|}{ Spesifikasi } & Keterangan \\
\hline 1 & Panjang & $47 \mathrm{~cm}$ \\
\hline 2 & Lebar & $25 \mathrm{~cm}$ \\
\hline 3 & Tinggi & $31 \mathrm{~cm}$ \\
\hline 4 & Ground Clearence & $4 \mathrm{~cm}$ \\
\hline 5 & Diameter ban & $3 \mathrm{inch}$ \\
\hline 6 & Berat & $3,2 \mathrm{~kg}$ \\
\hline 7 & Arus maksimal & $5 \mathrm{Ampere}$ \\
\hline 8 & Tegangan maksimal & $11,9 \mathrm{volt}$ \\
\hline 9 & Jangkauan sensor ultrasonik & $15 \mathrm{~cm}$ \\
\hline 10 & Jangkauan bluetooth & $15 \mathrm{~meter}$ \\
\hline 11 & Kecepatan angin fan penyedot & $5,8 \mathrm{~m} / \mathrm{s}$ \\
\hline 12 & Derajat belok roda & $50^{\circ}$ \\
\hline 13 & Noise & $90 \mathrm{~dB}$ \\
\hline
\end{tabular}

Dari pengukuran hardware pada Tabel 3 dimensi dari perangkat cukup mudah dioperasikan dalam ruangan besar maupun kecil dengan panjang $47 \mathrm{~cm}$, lebar $25 \mathrm{~cm}$, dan tinggi 
$31 \mathrm{~cm}$. sedangkan untuk kecepatan fan angin penyedot yang diukur dengan Anemometer bernilai $5,8 \mathrm{~m} / \mathrm{s}$ dan untuk noise yang diukur dengan dB meter bernilai kurang lebih $90 \mathrm{~dB}$.

\section{E. Hasil Pengujian Rangkaian Vacuum}

TABEL 4.PENGUJIAN VACUUM CLEANER

\begin{tabular}{|c|l|c|c|}
\hline No. & Jenis Kotoran & Jumlah & Keterangan \\
\hline 1 & Gula & $20 \mathrm{mg}$ & 17 detik \\
\hline 2 & Garam halus & $20 \mathrm{mg}$ & 11 detik \\
\hline 3 & Bubuk kopi & $20 \mathrm{mg}$ & 5 detik \\
\hline 4 & Potongan kertas & $20 \mathrm{mg}$ & 8 detik \\
\hline
\end{tabular}

Dari pengujian pada vacuum cleaner pada tabel 4 bahan atau debu dapat terhisap oleh vacuum cleaner seperti bubuk kopi, garam halus, dan potongan kertas. Pada jenis kotoran bubuk kopi vacuum cleaner dapat membutuhkan waktu 5 detik sedangkan yang paling lama dalam proses penyedotan dalam pengujian adalah proses pembersihkan gula dimana sebanyak 20mg gula membutuhkan waktu selama 17 detik.

\section{F. Persamaan Daya Hisap Vacuum Cleaner}

Mencari perhitungan daya hisap vacuum cleaner dapat diperoleh dari Persamaan 1.

$$
Q=V x A
$$

Keterangan dari persamaan 1 :

$\mathrm{Q}=$ kapasitas daya hisap vacuum cleaner $\left(\mathrm{m}^{3} / \mathrm{s}\right)$

$\mathrm{V}=$ kecepatan angin penghisap $(\mathrm{m} / \mathrm{s})$

A $=$ luas penampang lubang hisap $\left(\mathrm{m}^{2}\right)$

Berdasarkan persamaan 1, didapat perhitungan daya hisap vacuum cleaner sebagai berikut :

$$
\begin{aligned}
\mathrm{V} \quad=5,8 \mathrm{~m} / \mathrm{s} & \\
\mathrm{A} \quad=6,16 \mathrm{~m}^{2} & \\
Q & =V \times A \\
Q & =5,8 \mathrm{~m} / \mathrm{s} \times 6,16 \mathrm{~m}^{2} \\
Q & =35,728 \mathrm{~m} 3 / \mathrm{s}
\end{aligned}
$$

Adapun Luas penampang didapat dari Persamaan 2.

$$
\begin{aligned}
A= & \pi r \\
& \quad-\times 1,4 \times 1,4 \\
A= & 6,16 \mathrm{~m}^{2}
\end{aligned}
$$

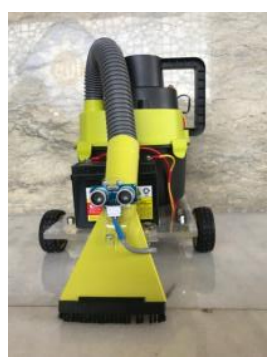

Gambar 7. Tampak depan Alat

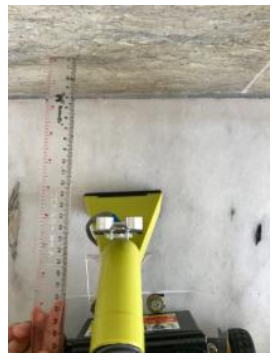

Gambar 8. Pengujian Sensor Ultrasonik

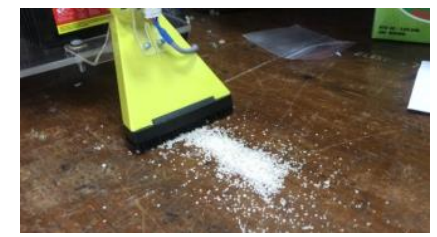

Gambar 9. Pengujian Vacuum Cleaner

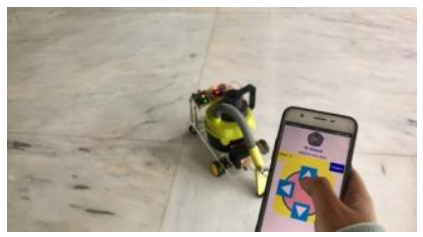

Gambar 10. Pengujian Aplikasi Android

\section{KESIMPULAN}

Berdasarkan hasil pengujian yang didapat dari perancangan alat pembersih lantai ini yakni alat ini dapat bergerak sesuai dengan perintah yang diinputkan melalui aplikasi android yang berupa gerakan maju, mundur, belok kanan, belok kiri maupun berhenti. Pada pengujian transmisi konektivitas melalui bluetooth alat ini dapat terhubung dengan jarak maksimal 17 meter dengan pemasangan sensor ultrasonik $12 \mathrm{~cm}$ dari ground. Sedangkan untuk kecepatan transfer data dapat terhubung dengan cepat tanpa delay pada jarak maksimal 12 meter. Pada pengujian sensor ultrasonik HC-SR04 dapat bekerja baik ketika sensor mendeteksi benda yang menhalangi minimum $15 \mathrm{~cm}$, maka buzzer akan berbunyi sebagai indikator bahwa ada halangan yang sangat dekat dengan alat ini. Rangkaian vacuum pada alat ini juga bekerja dengan baik yang dapat menghisap partikel-partikel kotoran dengan sempurna. 


\section{PERSANTUNAN}

Alhamdulillah puji syukur berkat Rahmat Allah SWT penulis dapat menyelesaikan tugas akhir ini dengan baik. Berkat Karunia-Nya pula penulis diberikan kemudahan dan dikelilingi orang - orang yang membantu dalam mengerjakan tugas akhir ini, maka penulis berterimakasih kepada :

1. Orang tua yang mendoakan dan menyemangati dalam mengerjakan tugas akhir ini.

2. Ketua Jurusan Teknik Elektro Universitas Muhammadiyah Surakarta Bapak Umar, S.T.,M.T. dan seluruh dosen Jurusan Teknik Elektro Universitas Muhammadiyah Surakarta.

3. Mahasiswa Teknik Elektro UMS, Khairunnisa Sekar R, Dimas Septian, Dian Arieska, Sadam Husein, Fatih, Muhammad Afan, Muhammad Bayu, Agnes Nita Wijayanti, Sri Indah Puja Ningsih, Amy Novalia, Rofika Ayuningtyas.

\section{DAFTAR PUSTAKA}

[1] Ardhi, Setya, dan Hari Sutiksno. 2016. Perancangan dan Pembuatan Prototipe Alat Pembersih Lantai dari Jaringan Bluetooth. Seminar Internasional dan Konferensi Nasional IDEC 2016.

[2] Monaiou-Olaru dan Nitulescu. 2011. Hexapod Robot. Virtual Models forPreliminary Studies, 1St International Conference on System Theory Control and Computing (ICSTCC).

[3] Muhira, Muhammad, dkk. 2017. Rancang Bangun Robot Pembersih Lantai Berbasis Arduino.

[4] Saniya, Nina dan Umi Fadillah. 2018. Alat Monitoring Suhu Kabel Trafo Berbasis Arduino dengan SMS.

[5] Sofana. 2008.Membangun Jaringan Komputer. Penerbit Informatika:Bandung.

[6] Rohmah, Ratnasari Nur, dan Laksono Budi Prianggodo. 2016. Rancang Bangun Robot Beroda dengan Object Tracking sebagai Dasar Pengendalian Gerakan Robot. Jurnal PROtek Vol. 03.

[7] Yongkui Ma, Yuming Wei, dkk.(2014). Design and Implementation of The Smart Home App Based on The Android System.China: Harbin Institute of Technology. 